\title{
Engaging Pellegrino's philosophy of medicine: Can one of the founders of the field still help us today?
}

\author{
Daniel P. Sulmasy ${ }^{1}$
}

Published online: 31 July 2019

(c) Springer Nature B.V. 2019

Many readers of Theoretical Medicine and Bioethics will be familiar with Edmund Pellegrino's work in medical ethics. His regularly featured column on ethics in the Journal of the American Medical Association (JAMA) acquainted even many general readers directly with his ethical thought. There is also a robust secondary literature that explores, critiques, and builds upon his ethics. Considerably less attention has been paid, however, to his philosophy of medicine. Given that Pellegrino thought that medical ethics was dependent upon the philosophy of medicine and given that he devoted a considerable portion of his scholarly writing to this topic, this lack of attention to his philosophy of medicine seems surprising. With this in mind, Dr. Kevin Donovan and the other organizers of the Fifth Annual Pellegrino Seminar decided to devote the 2018 meeting to engaging Pellegrino's philosophy of medicine. This special issue is the fruit of that effort.

Pellegrino wrote about a number of topics in the philosophy of medicine. He tried to explicate some of the logic of diagnosis and therapy, explored the meaning of medicine as a professional activity, and plumbed the relationship between biomedical science and the art of practice. He wrote about team care, prevention, and the relationship between medicine and society. He was deeply interested in the relationship between the philosophy of medicine and medical ethics.

Some invited contributors to the conference were already familiar with Pellegrino's work, but several were not. All were invited to write on specific aspects of his philosophy of medicine, but each was asked to engage that work constructively and critically. Those of us who knew Ed Pellegrino are certain he would not have wanted it any other way. I am sure he would have been thrilled to have engaged them all in extended discussion.

In the first essay in this collection, Patrick Daly argues that the avowed essentialism of Pellegrino's philosophy of medicine limits its capacity to address questions of medical science and questions of public health [1]. He offers, as an alternative,

Daniel P. Sulmasy

sulmasyd@georgetown.edu

1 Kennedy Institute of Ethics, Healy 419, Georgetown University, 3700 O St, NW Washington, DC 20057, USA 
Lonergan's generalized empirical method and his hierarchical account of world order as a foundation for a philosophy of medicine. This Lonerganian method corresponds well with Pellegrino's fundamental clinical questions-(1) What can be wrong? (2) What can be done? (3) What should be done?-but grounds them in the normative structure of human knowing rather than in a theory of the essence of medicine. The four Lonerganian questions occupy three levels that correspond almost exactly to those of Pellegrino: (1) What is going on? And is this so? (2) What is one to do? (3) Should I do it? Turning these questions to a broad understanding of health as a human good allows Daly to embrace clinical, scientific, and public health questions using the same structure of inquiry. He suggests that a more robust philosophy of medicine can be built upon this structure, but admits that doing so will require significant intellectual effort toward which his essay can only gesture.

In contrast to Daly, Kyle Karches fully embraces Pellegrino's Aristotelian-Thomistic essentialism, yet he argues that, taken seriously, it demands not only a telos for medicine but also a telos for human life [2]. Using the task of pain control in the setting of the present epidemic of opioid addiction as a timely example, he presses the case that treating pain cannot be understood as a goal for medicine, and that physicians will not know how best to utilize drugs and devices for its treatment, unless they understand how pain functions in human life, what it means to suffer, how human desires are fulfilled (or frustrated), and how such desires contribute to human flourishing. Provocatively, he raises the question of whether medical ethics needs not merely a philosophy of medicine, but really a theology of medicine.

Like Daly, James Marcum is troubled by the potential narrowness of Pellegrino's emphasis on the physician-patient relationship, yet Marcum also admires his insistence on the axiomatic primacy of the patient as central to the idea of medicine as a profession. He examines historically how first the "scientification" of medicine in the early twentieth century and then the commercialization of medicine in the late twentieth century have, successively, put pressure on the idea of medicine as a profession [3]. He proceeds to examine how Francis Peabody reacted to the first, and then how Pellegrino reacted to the cumulative effects of both the first and the second. He proposes as a remedy for the crisis in professionalism that these forces have engendered a cycle of professional activity that builds upon Pellegrino's tripartite model of the physician-patient relationship: the "fact of illness, act of profession, act of medicine" model. He explores how this model can be extended beyond the physician-patient relationship in the setting of a complex network model of health care delivery, a model that captures how contemporary health care now encompasses much more than the work of the physician. He argues that this entire network of care needs to be professionalized in this way in order to best serve the needs of the sick.

While his critics emphasize (and denigrate) the essentialist aspects of Pellegrino's philosophy of medicine, they often gloss over the very non-essentialist, nonAristotelian insights that are foundational to his project. Kay Toombs explores the phenomenological core of Pellegrino's philosophy of medicine-the patient's lived experience of illness [4]. She illustrates this theme autobiographically (and often wittily) with experiences she has had as someone living with multiple sclerosis. She concludes by invoking MacIntyre's notion of a moral community to ask whether 
Pellegrino's vision of health care can be sustained outside of some sort of intentional, shared community of value, such as the Christian community to which she belongs.

In light of a contemporary movement that demands "high value care," Matthew DeCamp explores what the term "value" might mean in the context of health policy [5]. He does so in a manner inspired by Pellegrino's work. Drawing on Pellegrino's fourfold notion of the patient's good, he proposes a conception of value in health care that is instrumental, agent-relative, and pluralistic. He uses that conception to critique those who would reduce the meaning of the word "value" to efficiency or cost-effectiveness. He also challenges the American health care system to incorporate a sense of the common good into its understanding of the ends of medicine and what makes health care valuable. He also notes that, if one takes value pluralism seriously, the attempt to commensurate all of the values of all the patients affected by health care policy decisions into a single grand calculus is a Sisyphean task. He notes that while many health policy analysts dream that such a calculus will be possible one day, he suspects that Pellegrino would only smile wryly as they plead their impossible cause.

The final essay, by Xavier Symons, is the winning submission to the 2018 inaugural Pellegrino Young Scholars Award. The Pellegrino Center for Clinical Bioethics intends to sponsor this competition annually, and Theoretical Medicine and Bioethics has agreed to publish each year's first prize essay for the foreseeable future. Winners must be graduate or professional students, resident physicians, or post-doctoral fellows. Symons, a graduate student in philosophy at the Australian Catholic University, examines the internalist, essentialist elements of Pellegrino's philosophy of medicine [6]. He then describes the criticisms of that position raised by Franklin Miller and Howard Brody, Robert Veatch, and Nuala Kenny. To defend Pellegrino against these critiques, he leans heavily on MacIntyre's neo-Aristotelian views as expounded in Dependent Rational Animals. He realizes that that this move is, of itself, insufficient to the task and suggests that the so-called New Natural Law Theory of John Finnis, Germain Grisez, Joseph Boyle, and their students might provide the necessary tools. He does not, however, undertake that task. Rather, he concludes that we will need to await future work (possibly from Symons himself) to judge whether this tack is successful.

Taken as a whole, these essays suggest that many of Pellegrino's ideas in the philosophy of medicine are not only relevant to contemporary discussions; they also remain illuminating and very useful. Some of his insights, to be sure, remain incompletely formed and invite further scholarly inquiry and development. Others just seem timeless and correct. His conception that medicine has an essence remains the most difficult of his ideas to defend, even by his most ardent disciples. Nonetheless, in pointing to the relationship between the patient and the health care professional as the core of what medicine is (and ever shall be), he makes a point that is novel in the philosophy of medicine and also seems hard to deny. I suspect that the philosophy of medicine will always be inadequate if it is incapable of embracing and explicating that claim. 


\section{References}

1. Daly, Patrick. 2019. Grounding medical ethics in philosophy of medicine: Problematic and potential. Theoretical Medicine and Bioethics 40. https://doi.org/10.1007/s11017-019-09491-y.

2. Karches, Kyle E. 2019. The ends of medicine and the crisis of chronic pain. Theoretical Medicine and Bioethics 40. https://doi.org/10.1007/s11017-019-09489-6.

3. Marcum, James A. 2019. Professing clinical medicine in an evolving health care network. Theoretical Medicine and Bioethics 40. https://doi.org/10.1007/s11017-019-09492-x.

4. Toombs, S. Kay. 2019. The healing relationship: Edmund Pellegrino's philosophy of the physician-patient encounter. Theoretical Medicine and Bioethics 40. https://doi.org/10.1007/s11017-01909490-z.

5. DeCamp, Matthew. 2019. Toward a Pellegrino-inspired theory of value in health care. Theoretical Medicine and Bioethics 40. https://doi.org/10.1007/s11017-019-09486-9.

6. Symons, Xavier. 2019. Pellegrino, MacIntyre, and the internal morality of clinical medicine. Theoretical Medicine and Bioethics 40. https://doi.org/10.1007/s11017-019-09487-8.

Publisher's Note Springer Nature remains neutral with regard to jurisdictional claims in published maps and institutional affiliations. 